\title{
Chi-Hé Elder
}

3

\section{[Pre-publication draft; not for distribution or quotation without permission]}

\begin{abstract}
This paper aims to bridge the relationship between metalinguistic 'if you like' as a nonpropositional discourse marker and its conditional counterparts. This paper claims that metalinguistic 'if you like' is polysemous between a hedge that denotes the speaker's reduced commitment to some aspect of the main clause, and an optional yet potential conditional reading that interlocutors can legitimately draw on in interaction which is brought about due to the 'if $p, q$ ' sentence form. That is, although the metalinguistic reading is most likely obtained automatically by default, it also carries an available conditional reading that is akin to other metalinguistic conditional clauses such as 'if you see what I mean'. Next, a semantic representation of metalinguistic 'if you like' is developed that takes on board a characterization of conditionality that departs from lexico-grammatical conventions, such that conditionals of the form 'if $p, q$ ' no longer bear a one-to-one correspondence with 'conditional' truth conditions. Employing a radical contextualist semantic framework in which the unit of truth-conditional analysis is not constrained to the sentence from, utterances employing metalinguistic 'if you like' are given a semantic representation such that the if-clause does not contribute propositional content, yet they also maintain their status as conditionals as the sentence form gives rise to a potential conditional secondary meaning.

Keywords: if you like, metalinguistic conditionals, explicit content, conceptual conditionals, radical contextualism

\section{$1 \quad$ Introduction}

Metalinguistic uses of 'if you like', as in (1), differ from 'standard' hypothetical conditional uses of 'if you like', as in (2). ${ }^{1}$

(1) So I went in with a bone of complaint, if you like. (ICE-GB S1A-064 142)

(2) We can have a competition if you like later on. (ICE-GB S2A-049 052)

The two uses differ as follows: in its hypothetical use, 'if you like' provides a condition on the truth or actualization of the proposition described in the consequent; in its metalinguistic use, 'if you like' hedges some aspect of the main clause as a metalinguistic comment.

Metalinguistic 'if you like' presents a puzzle for the semantics of conditionals insofar as it is typically viewed as a 'discourse marker' in linguistic analyses and, as such, does not contribute to the semantic (propositional) content of the utterance in which it occurs. As quoted in Heine (2013: 1206),

\footnotetext{
${ }^{1}$ Examples in the paper are predominantly taken from the Great British component of the International Corpus of English (ICE-GB). These are referenced using the standard notation from the spoken portion of that corpus, namely of the form (S00-000 000).
} 
[...] the status of discourse markers remains uncertain (see, for example, Fischer 2006). There is little consensus on whether they are a syntactic or a pragmatic category, on which types of expressions the category includes, on the relationship of discourse markers to other posited categories such as connectives [...] (Lewis 2011: 419-420, my emphasis)

This paper bridges the relationship between metalinguistic 'if you like' as a discourse marker and its conditional counterparts by addressing two questions. The first is whether metalinguistic uses of 'if you like' are, in fact, licensed in the category of 'conditionals' given that their primary function is to hedge some aspect of the main clause. I defend the view that while metalinguistic 'if you like' primarily functions as a non-propositional discourse marker, it gives rise to an optional yet potential conditional reading that interlocutors can legitimately draw on in interaction which is brought about due to the 'if $p, q$ ' sentence form. In other words, the meaning of 'if you like' is polysemous between its role as a hedge and its conditional meaning, and although the metalinguistic reading is most likely obtained automatically by default, it also carries an available conditional reading that is akin to other metalinguistic conditional clauses such as 'if you see what I mean'.

The second question that follows is how to semantically represent metalinguistic 'if you like' such that a unified analysis of metalinguistic conditionals and their hypothetical counterparts is possible. The polysemy account defended here departs from both 'semantic' approaches that postulate distinct lexical semantics for different uses of metalinguistic phenomena, and 'pragmatic' accounts that treat non-propositional readings of otherwise propositional phenomena as secondary inferences. It is the latter approach that is typically pursued for conditional utterances of the form 'if $p, q$ '. However, the challenge for including metalinguistic 'if you like' in the category of conditionals is that since its metalinguistic meaning is so well-entrenched, upholding the conditional reading as semantically prior to the metalinguistic reading is cognitively implausible.

To overcome this problem, I depart from the view that conditionals of the form 'if $p$, $q$ ' bear a one-to-one correspondence with 'conditional' truth conditions. To get the desired truth-conditional results for 'if you like', viz of $q$ simpliciter, I adopt the view from the radical contextualist theory of Default Semantics that the object of semantic, truth-conditional study is the primary intended meaning of the speaker (e.g. Jaszczolt 2010), where primary meanings are not necessarily informed by explicit linguistic content. Such a unit of semantic analysis draws on the conceptual structure of the primary intended speech act, rather than on the syntactic structure of the uttered sentence. By making this move, we can get the results that we want with respect to metalinguistic 'if you like': namely, utterances employing 'if you like' can retain their intuitive truth conditions where the if-clause does not contribute propositional content, yet they can also maintain their status as conditionals as the sentence form gives rise to a (potential) conditional secondary meaning. In other words, the metalinguistic meaning is arrived at directly, yet there is a potential conditional reading derived from the sentence form that can be drawn on by interlocutors.

With this overview in place, the structure of the paper is as follows. Section 2 describes the uses of functions of 'if you like', relating it to conditionals of the standard type. Section 3 discusses options for semantically representing metalinguistic 'if you like', before motivating metalinguistic 'if you like' as polysemous in Section 4. Section 5 introduces the 
pragmatic criteria for conditionality (withdrawn references) that allow 'if you like' to take on a conditional reading as a secondary inference, and Section 6 shows how it is possible to represent both the primary and secondary meanings of 'if you like' in the framework of Default Semantics. Section 7 summarizes the research and points to future directions.

\section{$2 \quad$ Motivating 'if you like' as conditional}

Uses of 'if you like' can broadly be divided into two categories based on their functions in English discourse: 'if you like' can function as a conditional clause proper, as in (2), or it can function as a metalinguistic comment, as in (1), repeated below.

(2) We can have a competition if you like later on.

(1) So I went in with a bone of complaint, if you like.

In (2), the truth or realization of $q$ is dependent on the truth of $p$. This use contrasts with that in (1), where the use of 'if you like' puts some aspect of $q$ into metalinguistic focus - in this case the phrase 'bone of complaint' - serving the function of commenting on the appropriateness or accuracy of the words uttered.

Uses of 'if you like' of the metalinguistic type can be further differentiated according to what is being hedged. Three hedging roles of 'if you like' are identified here. The first is as in (1), where 'if you like' comments on specific linguistic aspects of $q$. In this role, 'if you like' typically occurs with metaphors or figures of speech, such as the phrase 'bone of complaint' in (1); it also occurs when the speaker searches for a particular word as in (3), when qualifying the use of words that may not be familiar to the hearer, such as in (4) - which draws attention to terminology specific to an academic field - or when the speaker is not themselves comfortable with a particular expression or to acknowledge that the hearer may not accept its use, as in (5) with the word 'forced'. ${ }^{2}$

(3) The caricaturist $[\ldots]$ presents a kind of unrelenting, uh, sort of repetition of a particular way of looking at them, um, a particular image of them if you like. (ICE-GB S2A-057 072)

(4) And that is the prosodic effect, if you like, of the liquids in these words. (ICE-GB S2A030 034)

(5) More and more people are being, if you like, forced into the private sector. (ICE-GB S1B-039 102)

In all of these cases, the metalinguistic aspect can be emphasized by putting the target expression in quotation marks to indicate that something non-propositional is being hedged.

The second use of metalinguistic 'if you like' is where it hedges the overall illocutionary act of assertion, as in (6).

(6) So if you like, that is the definitive statement for the time being. (ICE-GB S1B-007 205)

\footnotetext{
${ }^{2}$ See Brinton (2008: 164-166) for analogous uses of metalinguistic 'if you will'.
} 
While in (1) we can put 'bone of complaint' in quotation marks to make manifest the exact word or phrase being hedged, in (6) there is no specific phrase that 'if you like' attaches to. Instead, 'if you like' hedges the assertion of the entire main clause, thereby signalling the speaker's awareness of the impropriety or controversy of making the assertion expressed in $q$.

The third use is that 'if you like' can hedge the propositional content of $q$. That is, rather than commenting on either the propriety of the words used or the speech act of assertion, it is the content of the assertion itself that is being hedged. Note that in (6), 'if you like' could plausibly function as both a hedge of the illocutionary act of asserting $q$, and of the propositional content of $q$, depending on the speaker's intended use. While this third use of 'if you like' does not concern linguistic characteristics such as form, pronunciation or choice of words, it can still be considered 'metalinguistic' on the basis that its primary function is to reduce the speaker's commitment to $q$ as opposed to contributing propositional content. ${ }^{3}$

Note that these three metalinguistic functions of 'if you like' can also be found in fully-fledged conditional sentence structures in which the if-clause makes those hedging roles explicit, exemplified in (7)-(9) respectively.

(7) It is still peanuts if you'll pardon the expression. (ICE-GB S2B-021 017)

(8) Very short skirt on if you don't mind me saying. (ICE-GB S1A-040 089)

(9) He came to you seeking to expand, if you agree with me. (ICE-GB S1B-064 132)

In (7), the if-clause comments on an aspect of the linguistic form of the consequent - the word 'peanuts' - thereby explicitly acknowledging that the choice of expression may not be accepted by the hearer. In (8), the if-clause acknowledges the potential impropriety of the speech act of asserting $q$. And finally, in (9), the if-clause hedges the propositional content of $q$, calling for the hearer's agreement on the content of the assertion.

These three uses of 'if you like', and by extension other metalinguistic if-clauses that overtly perform the same discursive function, appear to fall under Csipak's (2016) class of 'discourse-structuring conditionals' which satisfy the two defining features that (i) $p$ refers to a feature of the present discourse situation, as opposed to facts outside of the discourse situation, and (ii) $p$ cannot occur with past temporal reference. The latter feature is shown in the comparison between (10)-(12): while the past tense for both the hypothetical (10) and biscuit (11) conditionals are acceptable, in (12) it is not (examples from Csipak 2016).

(10) If Alex is in San Francisco right now, she is having iced coffee.

(10a) If Alex was in San Francisco yesterday, she was having iced coffee.

(11) If you are hungry right now, there are biscuits on the sideboard.

(11a) If you were hungry yesterday, there were biscuits on the sideboard.

(12) Alex is a little odd, if you know what I mean.

(12a) \# Alex was a little odd, if you knew what I meant yesterday.

It appears that all three of the metalinguistic uses of 'if you like' considered here fall under Csipak's definition of a discourse-structuring conditional - including those that hedge the

\footnotetext{
${ }^{3}$ Thank you to an anonymous referee for making me clarify this terminology.
} 
propositional content of $q$ - insofar as $p$ refers to some aspect of the present discourse situation, and likewise cannot occur with past temporal reference:

(6) So if you like, that is the definitive statement for the time being.

(6a) \# That was the definitive statement, if you liked yesterday.

(9) He came to you seeking to expand, if you agree with me.

(9a) \# He came to you seeking to expand, if you agreed with me yesterday.

However, where my category of metalinguistic conditionals comes apart from Csipak's 'discourse-structuring conditionals' is that she posits the additional defining feature that 'discourse-structuring conditionals' are 'biscuit conditionals' such as (14), to the extent that $q$ is considered true regardless of the truth of $p$, as opposed to hypothetical conditionals such as (13), in which the truth of $q$ is dependent on the truth of $p$.

(13) If John went shopping today, there are biscuits on the sideboard.

(14) There are biscuits on the sideboard if you want them. (Austin 1961)

However, as I show below, metalinguistic conditionals do not always satisfy the criteria for biscuithood.

Two standard tests (e.g. DeRose and Grandy 1999) to distinguish hypothetical conditionals from biscuit conditionals are the question (what if not- $p$ ?) and contraposition (if not- $q$ then not- $p$ ) tests, exemplified for (13) and (14) below-where (14a) and (14b) are infelicitous.

(13a) What if John didn't go shopping today? (There are no biscuits on the sideboard.)

(13b) If there are no biscuits on the sideboard, John didn't go shopping today.

(14a) \# And what if I don't want any? (There are no biscuits on the sideboard.)

(14b) \# If there are no biscuits on the sideboard, you don't want any.

On first glance, metalinguistic 'if you like' also appears to fail the tests for dependence between $p$ and $q$.

(1) So I went in with a bone of complaint, if you like.

(1a) \# And what if I don't like? (I didn't go in with a bone of complaint.)

(1b) \# If I didn't go in with a bone of complaint, then you don't like (it).

Such tests appear to license putting utterances using metalinguistic 'if you like' in the class of biscuit conditionals: $p$ and $q$ express independent propositions at the compositional level of the sentence. However, when 'if you like' hedges the propositional content of $q$, we get a different result.

(6) So if you like, that is the definitive statement for the time being.

(6b) And what if I don't like? (That is not the definitive statement.)

(6c) If that is not the definitive statement, you don't like (it). 
In this case, the truth of $q$ is dependent on the truth of $p$, and 'if you like' acts as a conditional clause with a hypothetical relationship between $p$ and $q$. So while metalinguistic conditionals share the features that $p$ refers to some aspect of the discourse situation and that $p$ cannot occur with past temporal reference, they are not uniquely a species of biscuit conditional as they can also take hypothetical readings.

We could posit a difference between the uses of 'if you like' that hedge the form or style of $q$ and those uses that hedge the content of $q$ : in the former, if the antecedent is denied by the hearer (however unnatural it may be to do so), the speaker can only retract the acceptability of the assertion, not the assertion itself. By contrast, in the propositional hedging uses, any denial of the antecedent would require the speaker to deny the truth of the consequent as well. Such a distinction would correspond to Declerck and Reed's (2001) difference between 'metalinguistic P-conditionals', in which the if-clause comments "on the choice of words in $[q]$ or on the pronunciation of a word" (2001: 353) and their 'contentevaluating-P conditionals', in which the if-clause comments on the content of $q$ (2001: 347).

However, the motivation for such a distinction is refuted by the fact that it is possible for a metalinguistic if-clause to target both linguistic aspects of $q$ and the propositional content of $q$, as in (7).

(7) Chris managed to solve the problem, if "manage" is the right word. (Dancygier 1999: 104)

First, the tests for hypotheticality are able to target the relevant linguistic aspect of $q$, namely the conventional implicature associated with 'manage' that solving the problem was in some way difficult for Chris. This is exemplified in (7a)-(7b).

(7a) What if "manage" is not the right word? (Chris did not "manage" to solve the problem.)

(7b) If Chris didn't "manage" to solve the problem, "manage" is not the right word.

This reading is made manifest by putting 'manage' in scare quotes - a case of metalinguistic negation. But equally, the tests can also target the entailed content of 'manage', namely that Chris solved the problem, as in $(7 \mathrm{c})-(7 \mathrm{~d}) .^{4}$

(7c) What if "manage" is not the right word? (Chris did not solve the problem.)

(7d) If Chris didn't solve the problem, "manage" is not the right word.

In either case, (7) passes the test for hypotheticality, refuting the hypothesis that hedges of form/style versus propositional content correspond to the categories of biscuit and hypothetical conditionals respectively. ${ }^{5}$ In other words, given that metalinguistic 'if you like'

\footnotetext{
${ }^{4}$ Dancygier's (1999) class of 'metatextual conditionals' also includes cases where the if-clause targets implicatures of $q$, such as in 'Chris managed to solve the problem, if solving it was at all difficult for him' (1999: 104). Discussion of such examples goes beyond the scope of this paper, where the focus is on the metalinguistic discourse marker 'if you like' and its status as conditional, although the semantic analysis offered in Section 6 is expected to be able to handle such cases.

${ }^{5}$ Substituting 'if you like' for the full phrase 'if "manage" is the right word' yields the same results.
} 
can satisfy a dependency relation between $p$ and $q$ when 'if you like' targets the propositional content of $q$, or even a conventional implicature available in $q$, suggests that the question of what is being hedged in a metalinguistic conditional cross-cuts the hypothetical-biscuit distinction. In turn, this throws caution to the view that metalinguistic 'if you like' is semantically distinct from its conditional, hypothetical use, thus lending credence to the aim of giving a uniform semantics of metalinguistic conditionals and hypothetical conditionals of the standard type.

\section{Semantics versus pragmatic accounts of metalinguistic markers}

While metalinguistic 'if you like' shares characteristics with both 'regular' conditionals of the hypothetical type, as well as fully-fledged if-clauses that make explicit their metalinguistic use, there is an outstanding question of whether 'if you like' as a discourse marker belongs to the realm of grammar in the first place. Metalinguistic 'if you like' fits in the category of discourse markers insofar as it fulfills a non-propositional, metadiscursive function (cf. Hansen 1998). ${ }^{6}$ But just because a given word or structure does not typically contribute to the propositional content of the utterance in which it occurs, does not automatically write it off as potentially fulfilling a propositional role, and hence the question of what kind of semantic analysis they can, or should, be given remains open.

The semantics of a number of other metalinguistic markers has been given recent attention, including of metalinguistic comparatives (e.g. Giannakidou and Yoon 2010, Morzycki 2011), metalinguistic '...ish' (Bochnak and Csipak 2014), and metalinguistic intensifiers (Morzycki 2012, Beltrama 2016), exemplified in (15)-(17) respectively. ${ }^{7}$

(15) Your problems are more financial than legal.

(16) They won the match...ish.

(17) Your shoes are downright huge.

These varying but related phenomena mirror metalinguistic 'if you like' insofar as they all signal an attitude toward some linguistic expression. Moreover, accounts of these phenomena cited above each aim to relate the metalinguistic uses of the respective markers to their 'ordinary' counterparts, showing how they share a common 'semantic core'. While the proposals differ in the details of their semantic treatments, what brings these accounts together is to treat the relevant metalinguistic marker as grammaticalized, and hence as a separate lexical item to their propositional counterparts. These accounts thereby favor what I term a semantic approach to the representation of meaning, in which different uses of the same word or structure give rise to independent readings which are determined presemantically. One item is thus ascribed several senses in the lexicon-one per meaning variation. The benefit of the semantic approach is that different readings can be derived without assuming one as 'semantically prior' to another. The parallels between the readings can be captured in the different lexical semantics while at the same time differentiating the

\footnotetext{
${ }^{6}$ As Heine (2013) points out, how to define a 'discourse marker' is not uniformly agreed; e.g. Siepmann (2005:

52) classes metalinguistic comments as 'second-level discourse markers'. I opt out of this debate and retain 'discourse marker' as a general term that indicates the non-propositional status of 'if you like'.

${ }^{7}$ Thank you to an anonymous reviewer for drawing my attention to these references.
} 
circumstances under which the metalinguistic reading occurs. ${ }^{8}$ This approach is best pursued when a metalinguistic phenomenon is considered grammatical, as opposed to pragmatic.

It may be tempting to consider 'if you like' grammaticalized on a par with the other metalinguistic markers described above given both its distinct distributional properties and pragmatic function to hypothetical conditionals. This would not be a surprising move given the diachronic evidence for 'if you like' as a metalinguistic marker, with the conditional use of 'if you like' dating from the mid-fifteenth century, and the non-conditional metalinguistic version coming in later at the end of the sixteenth century (Chen 1996). Indeed, Chen describes such if-clauses as 'deconditionalized', observing them as somehow resistant to formal reduction (Chen 1996). However, note the following passage from Fretheim et al (2003):

Parenthetical expressions like 'if you like' [...] constrain the speaker's ostensively communicated propositional attitude [...]. Their extra-clausal syntactic position and the lack of stress that goes with that position are indicative of a grammaticalization process involving the loss of truth-conditional meaning. (Fretheim et al 2003: 59, my emphasis)

Note that Fretheim et al refer to a process of grammaticalization; they do not state that 'if you like' is fully grammaticalized. In fact, as Hansen (1998) argues, discourse markers are necessarily not fully grammaticalized exactly because they are extra-clausal and do not make predictions about the syntax of their host units, and thus cannot constitute end points of the grammaticalization process. Hansen also reports a correlation between the 'semantic transparency' of discourse markers and their grammaticalization, to the extent that particlelike markers (such as 'well' and 'anyway') are opaquer in meaning and are closer to grammaticalization, while multi-word constructions (such as 'in other words') tend to retain compositionality and productivity in a way that is closer to their propositional uses, and hence are further from grammaticalization. This latter observation aligns with those made so far for the multi-word construction 'if you like' to the extent that its different uses can be considered more or less 'conditional' depending on what is being hedged, indicating a retention of compositionality that mirrors the canonical conditional use. It is therefore too strong a move to consider 'if you like' as grammaticalized, and hence the move to treat 'if you like' as syntactically and semantically distinct from other conditionals should be avoided.

An alternative, then, is to take a pragmatic approach to the problem, akin to Horn's (1989) seminal treatment of metalinguistic negation. On this kind of approach, a canonical, semantic, reading of a given phenomenon is assumed, while divergences from this reading

\footnotetext{
${ }^{8}$ We could go so far as to describe these accounts as positing lexical ambiguity between the metalinguistic and ordinary readings. But note that describing the lexical items as 'ambiguous' does not presuppose complete conceptual distinctness between the senses in the same way as for ambiguous nouns such as BANK (financial $^{2}$ institution) and $\mathrm{BANK}_{2}$ (riverside). In fact, the parallels between the metalinguistic and propositional versions are inevitable and expected given the diachronic relation between them; equally, because the metalinguistic markers are often in complementary distribution to their propositional counterparts - an indication of their grammaticalization - motivates postulating the different readings as due to their distinct lexical semantics. Rather, I use the term 'ambiguity' to refer to the level of representation at which the meaning variations occur. It is because meaning variations are accounted for at the semantic level that the same word/structure can be considered ambiguous, as multiple senses are not expected to co-occur in a given context of utterance. Thank you to an anonymous reviewer for making me clarify this point.
} 
are derived pragmatically. While Austin (1961) favored an ambiguity account to separate hypothetical from biscuit conditionals, the pragmatic account is generally preferred in the treatment of biscuit conditionals. The formal details differ between accounts, but the main idea is that the biscuit reading is derived as a pragmatic inference: since $q$ is independent from $p$, the speaker must have independent contextual reasons for asserting the conditional. Franke (2009) is a strong proponent of this pragmatic view, which has been followed and refined by Francez (2015) and Lauer (2014), among others. A Franke-style pragmatic analysis is also followed by Csipak (2016) for her category of discourse-structuring conditionals that are closely related to the class of metalinguistic conditionals as discussed in the previous section.

There are convincing arguments for this kind of unified position wherein different readings retain the same semantics, including the facts that both hypothetical and biscuit conditionals can be expressed using the same 'if $p, q$ ' sentence form, and that biscuit conditionals are well-attested across languages, indicating a systematic relationship between the two uses. Furthermore, given the prevalence of conditionals of the hypothetical type both in the literature on conditionals but also attested in language ${ }^{9}$, it is natural to posit noncanonical readings as deriving from the hypothetical type. However, treating the metalinguistic reading as a secondary inference has undesirable consequences for a semantic account that strives for cognitive reality. This is because - following the tradition in philosophical semantics and pragmatics (e.g. Recanati 2010, Carston 2002) - semantic, truthconditional content is assumed to be derived by automatic cognitive processes that stem from the logical form of the utterance, while pragmatic 'implicatures' are derived through secondary pragmatic processes. Taking the hypothetical reading to inform the semantics of 'if you like' would therefore come with the theoretical commitment that interlocutors entertain the hypothetical conditional reading first, and then override the mismatch with the metalinguistic reading. In other words, it would make the metalinguistic reading of 'if you like' a secondary inference that is obtained via an explicit-to-implicit, two-stage cognitive process. So even when Gricean implicatures are considered the main, intended meaning of a speaker (cf. Jaszczolt 2010), the pragmatic account assumes them to be recovered by the hearer due to the mismatch in the assumed intended content and the explicit content of what is said. ${ }^{10}$

What we want is to retain an element of both the semantic account - which would allow the metalinguistic reading primacy in the semantics of 'if you like' - and the pragmatic account, which would avoid 'multiplying senses beyond necessity' (Grice 1989: 47) and give a uniform semantics across uses. However, the struggle to do so seems to stem from the puzzle that 'if you like' presents in the determination of what counts as 'explicit meaning'. That is, while the conditional meaning is available due to the sentence form of the utterance in which it occurs and so appears the most likely candidate for explicit meaning, 'if you like' as a discourse marker makes the metalinguistic meaning no less explicit and certainly more automatic. What we seem to have is 'if you like' as a case of 'standardization', wherein

\footnotetext{
${ }^{9}$ (Withdrawn reference) finds $76 \%$ of if-conditionals in the ICE-GB to be hypothetical conditionals of the resultative or inferential type.

${ }^{10}$ This is the case even when a speaker only 'makes as if to say $p$ ', as Grice (1989: 30-31) purported for verbal irony. In this case, the speaker does not, in essence, say anything; yet the ironic message is still computed as a conversational implicature. Thank you to an anonymous reviewer for pointing this out as a comparison case.
} 
the hearer can reason directly, thanks to standardization, from the utterance to the indirect force, but the direct statement (in indicative cases) is always recoverable. (Bach 1995: 682)

In other words, the standardized metalinguistic meaning is the default, automatic meaning that a hearer is likely to recover, although the equally explicit, but conversationally dispreferred, hypothetical interpretation is nevertheless recoverable should the interlocutors choose to draw upon it. Indeed, the default interpretation of 'if you like' isn't even one that requires postulating 'unarticulated meanings' or a 'developed logical form' as on standard contextualist accounts (e.g. Recanati 2010, Carston 2002): the metalinguistic reading falls straight out of the use of 'if you like' as a discourse marker. The fact that we essentially have two options competing for the status of 'what is said', that is, the truth-conditional semantic meaning, both of which stem from the logical form, means that the dual-processing view of conditionals - and the explicit-implicit processing view of standard post-Gricean analyses falls down.

What I offer here instead is a third option: to treat 'if you like' as polysemous between its metalinguistic discourse marking function and its role as a conditional clause proper. This approach is motivated by the fact that one and the same utterance using 'if you like' can potentially give rise to both readings in the same context, warning against postulating separate lexical items for 'if'. Equally, it also avoids treating one reading as semantically prior to another: both readings are accessible, although given the salience of the metalinguistic reading, it is expected to be more consciously accessible.

\section{4 'If you like' as polysemous}

To treat 'if you like' as polysemous is to retain multiple senses of the if-clause as potentially present, allowing that more than one reading can be instantiated in a given context. This is different to treating the clause as structurally ambiguous with two distinct readings and then disambiguating the readings in context in virtue of the speaker's intended meaning. Rather, I use the term 'polysemous' to refer to the idea that both readings are accessible at the level of explicit meaning, and while one can be viewed as 'primary' (and hence 'semantic' - see Section 6) and the other as 'secondary', one can legitimately 'sentence-mean' both meanings in the same context. ${ }^{11,12}$ To be sure, the first sense is the metalinguistic one: the reading that is expected to arise automatically by default, and that has led others to treat 'if you like' as a discourse marker without propositional import. The second sense is the conditional one, which requires greater justification as constituting part of the explicit meaning of 'if you like'.

From a discursive point of view, we have seen that 'if you like' shares a discourse function with other fully-fledged conditional structures such as 'if you don't mind me saying'. But a brief diachronic story will elucidate that the relationship runs deeper than simply a pragmatic similarity. Looking at the analogous clause 'if you will', Brinton (2008) conjectures that 'if you will' arose as a shortened version of the overtly conditional 'if you are willing to

\footnotetext{
${ }^{11}$ The practice of keeping polysemous readings 'live' is what Nerlich and Clarke (2001) call 'ambiguating' in context - as opposed to 'disambiguating' in context.

${ }^{12}$ Note that availability of the metalinguistic reading is only applicable to metalinguistic conditionals in virtue of their pragmatic and distributional features described in Section 2 and is not expected to extend to all conditionals of the form 'if $p, q^{\prime}$. Thank to you an anonymous reviewer for suggesting this clarification.
} 
do so' that occurs in directive contexts, where both if-clauses play the same discursive role of hedging the illocutionary force of the directive issued in $q$. Specifically, she suggests that these directive contexts included verbs of 'saying' and 'calling' as in (18) (quoted after the OED), thereby extending the role of 'if you will' beyond that of a hedge of directive speech acts, to that of a metalinguistic hedge.

(18) Call them if you will, Popish fooles, and addleheads. (1641 'Smectymnuus', An Answer to a Booke entituled An Humble Remonstrance)

Brinton suggests that such utterances using verbs related to 'calling' provided a 'bridging context' that facilitated 'if you will' to undergo a semantic shift from the directive hedge 'if you are willing to do so' to the metalinguistic hedge 'if you are willing to say so'. As she says, while the illocutionary force of such utterances would be directive and would thus lead to the interpretation 'if you are willing to do so', the verb 'call' "invites the inference that supplies the metalinguistic sense 'if you are willing to say so'" (Brinton 2008: 178). This metalinguistic reading then applied beyond verbs that explicitly invoked the acts of calling or saying, and hence the metalinguistic use of 'if you will' extended beyond directive contexts.

Brinton's analysis suggests that metalinguistic 'if you will' arose directly from its conditional use. An analogous development of metalinguistic 'if you like' stemming from its conditional counterparts can plausibly be conjectured by the fact that we can find metalinguistic if-clauses using 'like' that explicitly specify the metalinguistic sense, as in (19) and (20) (quoted after the OED).

(19) "But why did he leave the half-million to his son, in his will?" "Gaga, my dear Binkie. Just gaga. Senile, if you'd like it better." (1929 W. J. Locke Ancestor Jorico xviii)

(20) A steady blasting of the ship's whistle sounded abandon ship that afternoon shortly before six bells, if you like nautical parlance. (1966 H. Brean Traces of Merrilee viii. 85)

These examples increase the plausibility that 'if you like' is related to fully-fledged if-clauses such as 'if you like what I'm saying' or 'if you like to call it that' that use 'like' as a verb of appreciation, and hence that the metalinguistic conditional reading of 'if you like' can be obtained compositionally from an interaction of its derivative parts. To treat 'if you like' solely as a discourse marker does not provide any explanation for how intuitively close in both form and content 'if you like' is with the if-clauses in (19) and (20). ${ }^{13}$

Acknowledging that metalinguistic 'if you like' retains a conditional meaning would allow for, and explain, the potential activation of dual readings when uttered in context. First, it is not only that bridging contexts with verbs of calling and saying support a diachronic relationship between 'if you will' and 'if you like' with their fully-fledged counterparts, but such contexts also highlight that the if-clauses can potentially take on both metalinguistic and hypothetical readings.

\section{(21) You could call it ingenuity if you like. (BNC, G4N 406)}

\footnotetext{
${ }^{13}$ Thank you to an anonymous reviewer for pointing this out.
} 
In (21), both a metalinguistic and a hypothetical reading of 'if you like' is available: putting the target content in quotation marks - 'ingenuity' - makes salient the metalinguistic reading, while the verb 'to call' provides the directive force on which 'if you like' can operate as a hypothetical condition akin to 'if you like to call it that'.

Note that it is not only in contexts of calling and saying that a dual reading is possible.

While the comic value of the opening prose arises by the speaker using 'if you like' as a metalinguistic comment while also commenting on others' use of 'if you like' in ordinary discourse, the addressee's clarificatory question 'if I like?' draws on the hypothetical use of 'if you like', thereby highlighting the two possible readings. Admittedly, the fact that certain constructions can be used as the source of linguistic jokes cannot be taken as evidence for how speakers use constructions in everyday conversation, nor as a test for positing different levels of representation (cf. Jaszczolt 2016: 24). But the fact that a certain construction has the potential to be exploited for its linguistic properties can be taken as evidence of the tacit knowledge that speakers have in their linguistic arsenal (e.g. Aarons 2012).

Finally, the availability of the conditional reading is perhaps more convincing when we see that a speaker can felicitously make reference to the audience's uptake, as in (22).

(22) We all know the feeling of walking round thinking something's missing. Sometimes it's our trousers, that's rectifiable. But sometimes it is, if you will, the trousers of meaning. Well, <laugh> I accept some of you won't. (BBC Radio 4 2016) ${ }^{14}$

Here, the speaker capitalizes on the use of 'if you will' to make it explicit that the target expression departs from certain conventions, and moreover, that a hearer may not accept its use. Although any elicited response is expected to be rhetorical at best, the 'if $p, q$ ' form nevertheless allows the hearer the potential to reject the phrase. That is, it is the form given by the if-clause that gives rise to a potential conditional reading that treating 'if you will' and 'if you like' solely as discourse markers would not allow.

To repeat, taking 'if you like' as polysemous is not to say that it requires disambiguating pre-semantically, but it is to retain both readings as 'live' options that can legitimately be drawn upon in interaction. To clarify, the two readings that are available are: (i) 'if you like' as a metalinguistic hedge, that indicates the speaker's reduced commitment to

\footnotetext{
${ }^{14}$ Mark Watson talks a bit about life. 2016. BBC Radio 413 September. http://www.bbc.co.uk/programmes/b07v0fv4 (accessed 14 September 2016).
} 
$q$ in some way, and (ii) the metalinguistic conditional reading, which allows the hearer to draw on the use of 'if' to refute the legitimacy of the assertion of $q$. While the metalinguistic meaning is arguably the most likely, primary meaning of 'if you like', the conditional reading is an optional secondary meaning that may or may not be activated by interlocutors.

\section{The semantic 'core' of conditionals}

The upshot of viewing 'if you like' as polysemous with a potential conditional meaning invites the question of what the semantic 'core' of conditionals is that unites conditional metalinguistic 'if you like' with hypothetical and biscuit conditionals. This section draws on previous work (e.g. withdrawn references), outlining two pragmatic criteria for delimiting the class of conditional utterances that places the notion of conditionality at a conceptual level. Such a view on conditionals avoids an ambiguity account of conditionals, while also desisting the conditional-first pragmatic view. The case of 'if you like' also provides additional justification for seeking such a pragmatic construal of conditionals in order that the conditional meaning can be viewed as a secondary, optional, meaning that is derived pragmatically, rather than as an underlying semantic meaning that needs overriding to obtain the metalinguistic reading. But the benefit of adopting pragmatic criteria is not only that they will admit if-clauses that are used to express either conditional or non-conditional meanings as primary, but they have the added explanatory power of showing how expressions without 'if', such as those in (23) to (25), express the intuitive conditionality that they do (cf. withdrawn references).
(23) Take one more step and I'll shoot.
(24) Your money or your life.
(25) You like it? It's yours.

Thus, not only do we move away from a semantic view of conditionals delineated by their truth conditions, but also from any definition that relies on specific lexical items or grammatical structures.

To capture conditionality as a concept at the level of thought, I class an utterance as conditional as long as

(a) the antecedent $p$ indicates remoteness; and

(b) $p$ restricts the situations in which $q$ holds.

The criteria are 'pragmatic' insofar as satisfying them is not a matter of structural or propositional constraints, but requires recourse to pragmatic processing and extra-linguistic information. Note that these criteria do not override more familiar syntactic or semantic criteria, insofar as utterances adhering to form-based definitions will also be admitted in the pragmatic category. The difference is that the pragmatic category is broader in scope, as it 
admits conditional thoughts that are expressed without using 'if' which would typically be excluded from structural definitions. ${ }^{15}$

\subsection{Remoteness}

The first criterion of remoteness stems from Grice (1967), who proposed a pragmatic solution to the fact that speakers do not always treat natural language conditionals as material conditionals. ${ }^{16} \mathrm{He}$ maintained that:

[...] in standard cases to say 'if $p$ then $q$ ' is to be conventionally committed to (to assert or imply in virtue of the meaning of 'if') both the proposition that $p \rightarrow q$ and the Indirectness Condition. (Grice 1967: 58)

In other words, an utterance of 'if $p, q$ ' adheres to the truth conditions as defined by the truth function of material implication and, in addition, there is a Generalized Conversational Implicature that there are non-truth-functional grounds for making the assertion (the Indirectness Condition). To put it another way, an utterance of 'if $p, q$ ' is expected to be uttered in accordance with the Cooperative Principle, and thus if the speaker had evidence for a stronger statement, for example using 'since' in place of 'if', he/she should have said so.

Without taking on the view that natural language conditionals behave as material conditionals, we can generalize Grice's proposal to the extent that use of the word 'if' signifies that the speaker does not present the antecedent as certainly true. Of course, not all conditionals are expressed using 'if', so to take the burden off any single lexical item, we can offer the more general statement that this uncertainty - what I call 'remoteness' - is a feature of the antecedent $p$ in general.

Conditional metalinguistic 'if you like', both following the 'if $p, q$ ' sentence form and using the canonical conditional marker 'if', satisfies the requirement of remoteness automatically in virtue of its form. That is, the conditional reading is obtained compositionally from its constituent parts, and so 'if you like' presupposes that the speaker does not expect the hearer to automatically accept $q$, and hence does not presume that $p$ is true.

It may be noted at this point that some antecedents, such as that in (26) appear to violate the remoteness requirement in virtue of being objectively true.

(26) If Jones had taken arsenic, he would have shown just exactly those symptoms which he does in fact show. (from Anderson 1951: 37)

On this I maintain that, regardless of whether $p$ is true in the actual world, by putting $p$ in a conditional structure, it is presented as unknown and thereby suspends the speaker's own

\footnotetext{
15 The criteria are inclusive of syntactic or grammatical definitions of conditionals insofar as if, in the future, some if-clause were to become grammaticalized with no conditional import, those if-clauses would not satisfy the syntactic definition of conditionality in virtue of being separate grammatical markers. Thank you to an anonymous reviewer for making me clarify this point.

16 There are ample studies showing that speakers do not process natural language conditionals as material conditionals (see e.g. Evans and Over 2004).
} 
assessment on the actual state of affairs. Even if the truth of $p$ is made explicit, for example by adding 'and he has' after the antecedent in $(26),{ }^{17}$ it is by couching the true state of affairs in an if-clause that allows the speaker to construct a convincing argument: $p$ is presented as remote precisely in order to argue that $p$ is true. So regardless of whether the speaker is actually committed to the truth of $p$, by presenting it in a conditional utterance, the speaker signals that it is not, at least for the purpose of the utterance at hand, presupposed. In the case of 'if you like', remoteness is satisfied through the positive politeness strategy of not assuming the hearer will accept the assertion of $q$, regardless of whether the speaker believes that $q$ will actually be accepted.

\subsection{Restriction}

Next, the possible worlds account of conditionals finds its roots in Stalnaker (1975), and it is from here that the second criterion of restriction stems. Motivated by the pitfalls of the material conditional as an analogue to natural language conditionals, Stalnaker proposed the following:

[...] a conditional statement, if $\mathrm{A}$, then $\mathrm{B}$, is an assertion that the consequent is true, not necessarily in the world as it is, but in the world as it would be if the antecedent were true. (Stalnaker 1975: 68)

Clearly, many conditional utterances do not lend themselves to a truth-conditional account of this sort, and these truth conditions will not adequately extend to biscuit conditionals where $p$ does not restrict the truth of $q$. But what this truth-conditional theory provides us with is a way of thinking about conditional utterances that relies on restricting our attention to those situations where $p$ obtains. This is the second criterion for inclusion in the class of conditional utterances: that the consideration of $q$ is restricted to those situations that are specified by $p$.

It should not be unsurprising then that, unlike Stalnaker's truth conditions for conditional assertions, this criterion need not be satisfied in terms of truth and falsity but may be satisfied in terms of $p$ narrowing the field of discourse such that $q$ is felicitously uttered. This more pragmatic notion of restriction gives rise to the familiar view of biscuit conditionals in which $p$ clearly does not restrict the worlds in which $q$ is true, but rather, indicates the situations where uttering $q$ is relevant. In the case of metalinguistic conditionals, $p$ specifies the condition on which uttering $q$ is appropriate.

'If you like' satisfies the criterion of restriction in different ways depending on what is being hedged. When 'if you like' hedges some aspect of the form of $q$, as in (1) repeated below, it satisfies the criterion in the same way as other metalinguistic if-clauses by providing a restriction on the situations where $q$ is felicitously uttered - and specifically to those situations where the hearer accepts $q$.

(1) So I went in with a bone of complaint, if you like.

That is, 'if you like' restricts the acceptance of $q$ to those situations where the hearer does, in fact, like (or accept) what is being uttered in $q$.

${ }^{17}$ Thank you to an anonymous reviewer for drawing my attention to this possibility. 

you like' satisfies the restriction criterion in the same way as regular, hypothetical conditionals.

So if you like, that is the definitive statement for the time being.

That is, the truth of $q$ is restricted to exactly those situations where $p$ obtains - again, namely where the hearer accepts the content of $q$. This comes directly from the content of the ifclause, where 'if you like' targets the hearer's acceptance of $q$ via the verb of desire. In this case, it is possible to refute the truth of $q$ by refuting the truth of $p$ (cf. (6b) and (6c) in Section 2). underlying conditional semantics of 'if you like', allowing the if-clause to retain its status as a discourse marker, while making available conditionality as a potential secondary meaning for interlocutors to draw upon. The final task is to show how we can semantically represent utterances using 'if you like' such that they retain conditionality as a potential meaning, without the consequence that the if-clause must contribute to the propositional content of the utterance. In the following section, I propose a solution that departs from the explicit-toimplicit processing route of conditional utterances, in favor of one that prioritizes the automatic, default meaning for the status of 'what is said' - namely, the metalinguistic reading - and hence informing the truth-conditional content of the utterance.

\section{Representing metalinguistic conditionals in Default Semantics}

The option I pursue here as an alternative to the semantic and pragmatic approaches to metalinguistic markers described in Section 3 is that offered by the radical contextualist theory of Default Semantics (e.g. Jaszczolt 2010). There are many varieties of semantic contextualism, but generally speaking, they are guided by the overarching principles that truth conditions are not constrained by the sentence form, and that context is allowed to play a significant role in determining the truth-conditional unit. However, while on 'standard' contextualist analyses both 'bottom up' and 'top down' processes are allowed to operate on the words uttered to produce an enriched, 'developed' (e.g. Carston 2002) or 'modulated' (e.g. Recanati 2010) logical form, the downside to these proposals is that 'what is said' (truthconditional content) is mandated by the output of grammar and is logically prior to 'what is implicated'. The problem of taking this approach for 'if you like' stems from the question of what counts as its explicit meaning, and whether the metalinguistic reading or the hypothetical reading should take precedence as constituting the 'output of grammar'.

In contrast to these approaches, in Default Semantics the logical form of the utterance is allowed to be overridden to align with the primary, intended meaning of that utterance. The upshot of this move is that truth conditions may be predicated of a unit which corresponds to the syntactic form of the uttered sentence to varying degrees. In the case of 'if you like', it is not that the logical form needs overriding per se, but simply that the if-clause should not contribute to truth-conditional content. But the benefit of potentially overriding the logical form as is admitted by Default Semantics is that the traditional two-tiered theory consisting of 'what is said' (including developments of the logical form, modulated senses, or free pragmatic enrichment, depending on one's contextualist theory) and 'what is implicated' 
(meanings expressed that go beyond the scope of the syntactic form of the utterance) is collapsed to a one-tiered theory. The logical form of the sentence is not given any preferential status in the model of meaning but is treated as just one source of information that contributes towards generating the primary meaning, and hence unit of truth-conditional analysis.

Note that on such a one-tiered theory, conditional sentences (of the form 'if $p, q$ ') with a non-conditional primary meaning, as in the case of 'if you like', will still retain a potential conditional meaning that is borne out of the sentence form. However, the explicit conditional meaning that pertains to the 'if $p, q$ ' sentence retains the status of a secondary meaning, roughly corresponding to an 'implicature' in Gricean pragmatics, which may or may not be activated by interlocutors in conversation. However, the difference between the post-Gricean contextualist accounts briefly mentioned above and the one-tiered version of Default Semantics, is that in the latter, the statuses of propositional content (primary meanings) and implicatures (secondary meanings) are no longer tied to a distinction between explicit, uttered content, and implicit, recovered content. Rather, the explicit/implicit distinction cuts across the primary/secondary distinction: the explicit content from a conditional sentence may take the role of a secondary meaning, while an implicitly recovered conditional meaning may constitute the primary meaning, and vice versa. And in the case of 'if you like', we don't even have to commit to there being one explicit meaning: the primary function of 'if you like' in a given context is likely to be as a discourse marker that hedges some aspect of $q$, while the form of 'if you like' also makes available a potential secondary meaning of conditionality that may or may not be activated in different contexts.

Treating the metalinguistic reading as primary and the hypothetical reading as secondary is a controversial move that counters much of the extant philosophical and linguistic literature on conditionals. As such, it is worth expanding on its theoretical implications. First, it has to be emphasized that the account defended here prioritizes primary, intended meanings in the construction of semantic representations. This means that, in line with the more familiar view on the semantics of conditionals, for 'ordinary' conditionals of the hypothetical type for which the hypothetical meaning is the primary one, the hypothetical meaning will take precedence in the semantic truth-conditional representation. But this is in virtue of equating primary meanings with truth-conditionals meaning, and not because the explicit sentence meaning is solely responsible for deriving semantic content. As discussed by (withdrawn references), conditional sentences displaying a hypothetical relationship between $p$ and $q$ at the level of the logical form are not always used to communicate hypothetical conditional primary meanings, nor are all biscuit conditionals used to communicate non-conditional primary meanings. As such, a major benefit of taking primary meanings as the object of truth-conditional study is that we can offer a uniform semantic account of the conditional and non-conditional meanings that are expressed using the same 'if $p, q^{\prime}$ sentence form - as well as conditional meanings expressed using non-canonical forms, as hinted in Section 6 - that is faithful to the cognitive processing of meanings as they are automatically used and recovered in context irrespective of the sentence form by which they are carried.

To finish, I briefly outline the key principles of Default Semantics (henceforth DS) that will be sufficient for demonstrating how we can represent the relevant meanings of 'if you like'. Note that DS is not the only framework available for such an analysis, and full explication of the details of the theory would take us beyond the scope of this paper. What I detail below is an illustration of how interlocutors are presumed to arrive at the potential 
primary and secondary meanings inferred from utterances using 'if you like', as DS offers conceptual representations pertaining to speakers' general cognitive mechanisms. ${ }^{18}$

First, DS takes compositionality as a methodological assumption, but rather than applying it at the level of sentence meaning, uses it at a higher level of representation at which different sources of information contribute to the composition of meaning. DS identifies five different sources of information pertaining to both linguistic and extralinguistic information, namely: (i) word meaning and sentence structure, (ii) world knowledge, (iii) situation of discourse, (iv) stereotypes and presumptions about society and culture, and (v) properties of the human inferential system. Next, DS identifies four potential processes that can operate on the material taken from these sources of information: of relevance to us here are (i) word meaning and sentence structure (WS: note that this is both a source of information and a process), and (ii) social, cultural and world knowledge defaults (SCWD). Finally, these processes culminate in a merger of information ( $\Sigma$ for 'summation') that in turn outputs the primary meaning of a given utterance. It is important to note that for different utterances and in different contexts, the sources (and processes operating on them) will contribute to the merger of information in greater or lesser degrees. WS is the source that pertains to the logical form of the sentence, including word meanings and sentence structure, but, crucially, is regarded as just one of several sources of information and can be overridden by the output of other sources if the context requires it. So to summarize, both primary meanings and secondary meanings are modeled as the output resulting from the merger of information coming from the different sources of information.

With this brief overview in place, we can now move to represent conditional utterances using these tools. For the standard cases of conditional sentences with a conditional primary meaning, the content of that primary meaning comes directly from the logical form of the sentence, that is, the source WS. Figure 1 represents the conditional meaning stemming from the literal use of 'if you like' in (2).

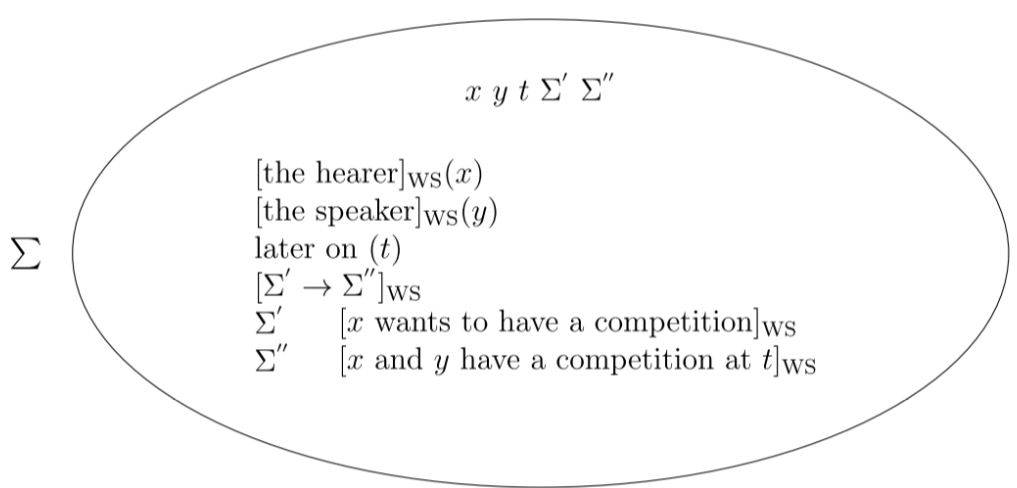

Figure 1: $\sum$ for conditional primary meaning of (2): 'We can have a competition if you like later on'

The discourse referents are denoted by $x, y, \Sigma^{\prime}$ and $\Sigma^{\prime \prime}$, and the discourse conditions follow underneath in square brackets. The subscript after the square brackets refers to the type of process operating on the content inside the brackets. And as we can see from the

\footnotetext{
${ }^{18}$ Interested readers are directed to Jaszczolt (2010) for a more detailed overview of the theory, as well as (withdrawn reference) on representing conditional utterances both with and without 'if'.
} 
representation, it is only WS that plays a role in generating the required meaning, and the 'standard' conditional truth conditions can be applied to this unit of analysis.

Crucially, what the composition of processes allows us to do is to represent the nonconditional meaning that is the primary, intended content of a conditional using metalinguistic 'if you like' such as (1), as in Figure 2.

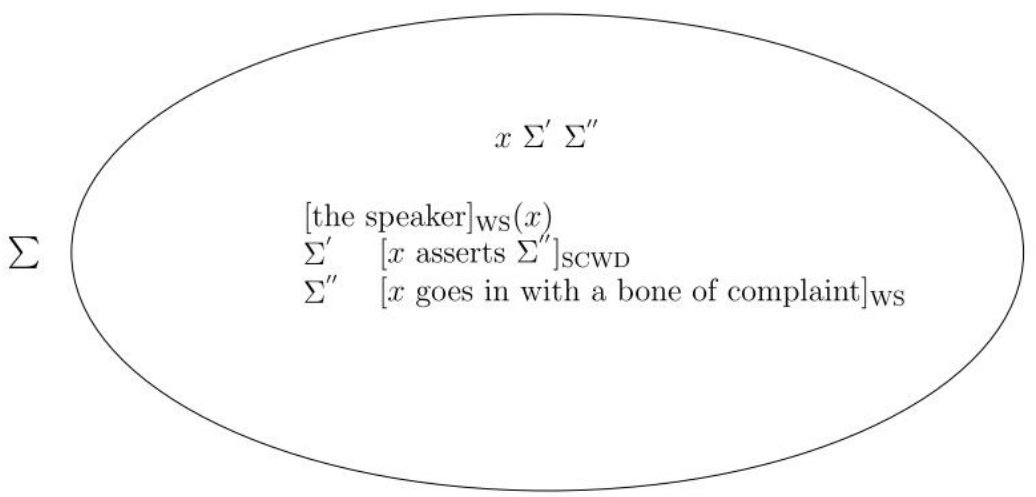

Figure 2: $\sum$ for metalinguistic primary meaning of (1): 'I went in with a bone of complaint, if you like'

The primary meaning pertaining to $q$ comes about due to an interaction of the logical form, the source WS, with the fact that speakers know how 'if you like' is intended to be understood; in other words, it is due to the hedging role of $p$ that the hearer is able to recover that the main message pertains to $q$ alone. This tacit knowledge is attributed as a default of the SCWD (social, cultural and world knowledge) type.

Finally, the conditional secondary meaning can be represented as in Figure 3, highlighting that the speaker's assertion is only accepted when it is deemed felicitous by the addressee.

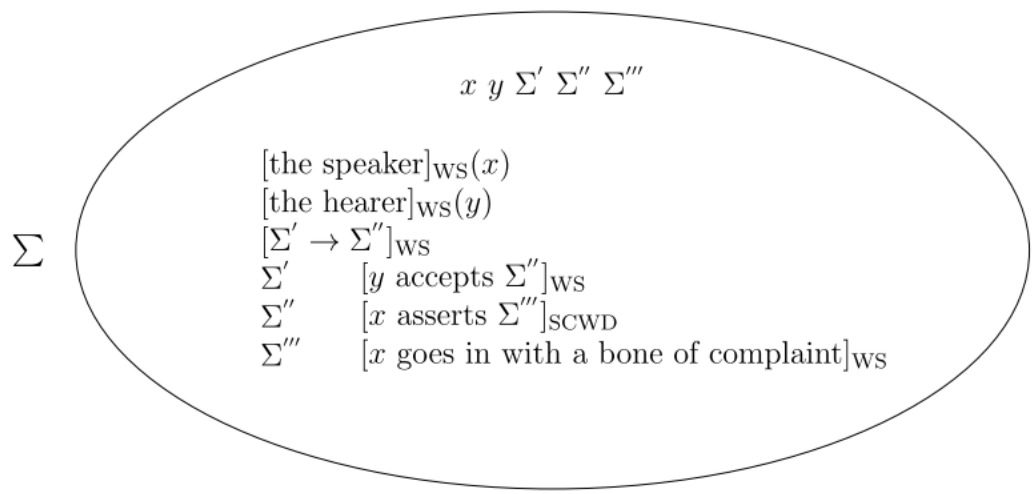

Figure 3: $\sum$ for conditional secondary meaning of (1): 'I went in with a bone of complaint, if you like'

Here, the logical form is again responsible for generating this secondary meaning, but we add in an extra processing step, namely the one in which $q$ is only accepted into the discourse on 
such as (8) (repeated below) would be represented analogously, where $q$ is deemed to be conditional on the felicity of its utterance.

(8) Very short skirt on if you don't mind me saying.

However, other biscuit conditionals would differ in the details, depending on what exactly is conditional: whether that be the relevance of an assertion, a condition for an offer, and so forth. Giving the exact representations for such conditional meanings is a task for another day.

To sum up, by taking on board a truth-conditional unit that pertains to a higher level of representation than that of the uttered sentence form, we are able to represent the main, intuitive content that is communicated via 'if you like'. Such representations are easily extendable to other utterances whose conditional meaning may be either primary or secondary. But in addition, we are also able to obtain the desired result that conditional meanings communicated by non-standard conditionals such as 'if you like' retain their conditionality as secondary meanings without the consequence that $p$ has to contribute to the truth-conditional, semantic content of the utterance. This is because although conditionality is intrinsically linked to the sentence structure, it plays a dual role of a discourse marker that gives rise to the non-conditional truth-conditional unit.

\section{$7 \quad$ Concluding remarks}

This paper has analyzed utterances using metalinguistic 'if you like' in light of their apparent mismatch in conditionality and truth conditions, and in doing so I hope to have shown that the status of 'if you like' as a discourse marker and its conditionality need not be mutually exclusive. This has been achieved by first viewing 'if you like' as polysemous, with a dominant metalinguistic hedging reading, and an additional, optional, conditional meaning that can legitimately be activated by interlocutors in discourse. 'If you like' is thus co-opted in the conceptual category of conditionals at large that takes pragmatic criteria for its delineation. This category encompasses conditionality either expressed as the primary, intended meaning of the speaker, or as a secondary meaning that is derived via pragmatic processing. While this is admittedly still a two-step processing view of metalinguistic conditionals, it is a move away from the 'explicit-first' view. This is because the primary nonconditional meaning of a hedge is obtained automatically by default, while the conditional meaning would only likely be recovered as a secondary 'implicature'. The upshot is that by taking the primary meaning as the truth-conditional unit, 'if you like' need not contribute to the truth conditions of the utterance in which it features, but it does contribute to conditionality.

It is not a far step away to apply this analysis to other metalinguistic conditionals which perform the same pragmatic function in discourse. While if-clauses such as 'if I may say so', 'if you see what I mean', and so forth are less clear-cut as belonging to the class of discourse markers in the strict sense, they are nevertheless used to communicate the same metalinguistic meaning. In this sense, they also have the same duality of explicit meaning, where the metalinguistic hedge is the default, automatic reading, yet the more overtly conditional reading is still recoverable. Note that when we move away from the specific case of metalinguistic conditionals, there is the added consideration that both hypothetical and 
biscuit conditionals can be used to communicate speech acts other than straightforward assertion (hence the term 'speech-act conditional'), in which case the explicit meaning would require overriding altogether to obtain the desired primary meaning. This is only possible on an account that breaks away from the view that conditional meanings are equated with conditional truth conditions. What I have proposed instead is a reconceptualization of what it is to be conditional which is not tied to truth-conditional content, which allows us to target the primary speech-act as the semantic content.

\section{References}

Aarons, Debra. 2012. Jokes and the linguistic mind. New York: Routledge.

Anderson, Alan Ross. 1951. A note on subjunctive and counterfactual conditionals. Analysis 12(2). 35-38.

Austin, John Langshaw. 1961. Ifs and cans. In J. O. Urmson \& G. J. Warnock (eds.), Philosophical papers, 153-180. Oxford: Oxford University Press.

Bach, Kent. 1995. Standardization vs. conventionalization. Linguistics and Philosophy 18(6). 677-686.

Beltrama, Andrea. 2016. Exploring metalinguistic intensification: The case of extreme degree modifiers. In Christopher Hammerly \& Brandon Prickett (eds.), Proceedings of the forty-sixth annual meeting of the North East Linguistic Society, 79-92. Amherst, MA: GLSA.

Bocknak, Ryan \& Eva Csipak. 2014. A new metalinguistic degree morpheme. In Todd Snider, Sarah D'Antonio \& Mia Weigand (eds.), Proceedings of the $24^{\text {th }}$ Semantics and Linguistic Theory conference (SALT), 432-452. LSA and CLC Publications.

Brinton, Laurel J. 2008. The comment clause in English: Syntactic origins and pragmatic development. New York: Cambridge University Press.

Carston, Robyn. 2002. Thoughts and utterances: The pragmatics of explicit communication. Oxford: Blackwell Publishing.

Csipak, Eva. 2016. Discourse-structuring conditionals and past tense. In Proceedings of Sinn und Bedeutung 21. Preprint available online: https://sites.google.com/site/sinnundbedeutung21/proceedings-preprints

Dancygier, Barbara. 1999. Conditionals and prediction. Cambridge: Cambridge University Press.

Declerck, Renaat \& Susan Reed. 2001. Conditionals: A comprehensive empirical analysis. Berlin, New York: Mouton de Gruyter.

DeRose, Keith \& Richard E. Grandy. 1999. Conditional assertions and 'biscuit' conditionals. Noûs 33(3). 405-420.

Evans, Jonathan St. B. T. \& David E. Over. 2004. If. Oxford: Oxford University Press.

Fischer, Kerstin (ed.). 2006. Approaches to discourse particles. Bingley, UK: Emerald Group Publishing.

Francez, Itamar. 2015. Chimerical conditionals. Semantics and Pragmatics 8. 1-35.

Franke, Michael. 2009. Signal to act: Game theory in pragmatics. Ph.D. thesis, FGw: Institute for Logic, Language and Computation (ILLC).

Frayne, Michael. 2014. Twelfth night, or if you like, timon of athens. In Matchbox Theatre, 200-204. Faber \& Faber 
Fretheim, Thorstein, S. Boateng \& I. Vaskó. 2003. Then - adverbial pro-form or inference particle? In Ken Turner \& Kasia M. Jaszczolt (eds.), Meaning through language contrast, 51-74. Amsterdam, Philadelphia: John Benjamins Publishing Company.

Giannakidou, Anastasia \& Suwon Yoon. 2010. The subjective mode of comparison: Metalinguistic comparatives in Greek and Korean. Natural Language and Linguistic Theory 29(3). 621-655.

Grice, Paul. 1967. Indicative conditionals. In Studies in the way of words, 1989, 58-85. Cambridge, MA: Harvard University Press.

Grice, Paul. 1989. Studies in the way of words. Cambridge MA: Harvard University Press. Hansen, Maj-Britt Mosegaard. 1998. The semantic status of discourse markers. Lingua 104(1998). 235-260.

Heine, Bernd. 2013. On discourse markers: Grammaticalization, pragmaticalization, or something else? Linguistics 51(6). 1205-1247.

Horn, Laurence R. 1989. A natural history of negation. Chicago: University of Chicago Press.

Lauer, Sven. 2014. Biscuits and provisos: Conveying unconditional information by conditional means. In Eva Csipak \& Hedde Zeijstra (eds.), Proceedings of Sinn und Bedeutung 19, 357-374.

Lewis, Diana M. 2011. A discourse-constructional approach to the emergence of discourse markers in English. Linguistics 49(2). 415-443.

Jaszczolt, Kasia M. 2010. Default Semantics. In Bernd Heine \& Heiko Narrog (eds.), The Oxford handbook of linguistic analysis, 193-221. Oxford: Oxford University Press

Jaszczolt, Kasia M. 2016. Meaning in linguistic interaction: Semantics, metasemantics, philosophy of language. Oxford: Oxford University Press.

Kamp, Hans \& Uwe Reyle. 1993. From discourse to logic: Introduction to model theoretic semantics of natural language, formal logic and Discourse Representation Theory. Dordrecht: Kluwer Academic Publishers.

Morzycki, Marcin. 2012. Adjectival extremeness: Degree modification and contextually restricted scales. Natural Language and Linguistic Theory 30(2). 567-609.

Morzycki, Marcin. 2011. Metalinguistic comparison in an alternative semantics for imprecision. Natural Language Semantics 19(1). 39-86.

Nerlich, Brigitte. and Clarke, David D. 2001. Ambiguities we live by: Towards a pragmatics of polysemy. Journal of Pragmatics, 33(1).1-20.

Recanati, François. 2010. Truth conditional pragmatics. Oxford: Oxford University Press. Siepmann, Dirk. 2005. Discourse markers across languages. London, New York: Routledge. Stalnaker, Robert. 1975. Indicative conditionals. In Context and content, 1999, 63-77. Oxford: Oxford University Press. 